\title{
HIGH-RESOLUTION SOIL MOISTURE MAPPING USING OPERATIONAL OPTICAL SATELLITE IMAGERY
}

\author{
Jan M.H. Hendrickx ${ }^{1}$, J. Bruce J. Harrison, Brian Borchers, and Graciela Rodríguez-Marín \\ New Mexico Tech, Socorro, NM 87801 \\ Stacy Howington and Jerry Ballard \\ Coastal and Hydraulics Laboratory, Engineer Research and Development Center \\ Army Corps of Engineers, Vicksburg, MS 39180-6199
}

\begin{abstract}
Soil moisture conditions have an impact upon virtually all aspects of Army activities and are increasingly affecting its systems and operations. Soil moisture conditions affect operational mobility, detection of landmines and unexploded ordinance, military engineering activities, blowing dust and sand, watershed responses, and flooding. This study explores a novel method for high-resolution $(2.7 \mathrm{~m})$ soil moisture mapping using remote satellite optical imagery that is readily available from Landsat and QuickBird. The soil moisture estimations are needed for the evaluation of sensors for Improvised Explosive Devices (IEDs) using the Countermine Simulation Test Bed in regions where access is denied. The method has been tested in Helmand Province, Afghanistan, using a Landsat7 and a QuickBird image of April 23 and 24,2009 , respectively. The first implementation of the method yielded promising results.
\end{abstract}

Keywords: soil moisture, Landsat, QuickBird, IED, Helmand, Afghanistan

\section{INTRODUCTION}

Soil moisture conditions have an impact upon virtually all aspects of Army activities and are increasingly affecting its systems and operations. Soil moisture conditions affect operational mobility ${ }^{[1]}$, detection of landmines and unexploded ordinance $^{[2-10]}$, military engineering activities, blowing dust and sand, watershed responses ${ }^{[11-15]}$, and flooding ${ }^{[16,17]}$. Soil moisture also determines near-surface atmospheric conditions and the partition of incoming solar and long-wave radiation between sensible and latent heat fluxes ${ }^{[18,19]}$. Atmospheric turbulence can hamper the performance of optical and infrared sensors as well as acoustic detection systems. The lack of reliable soil moisture maps for weather prediction models can result in significant over- or under-estimation of surface evaporation which results in great uncertainty for the predictions of cloud cover, precipitation, air and soil temperature, and humidity ${ }^{[20]}$.

Spatial scales of interest range from the theater scale (maneuverability), watershed scale (river crossing), field scale (trafficability), and sub-meter scale (IED and land mine detection). Soil moisture at each of these scales is a very dynamic variable subject to rapid changes in time as well as with depth and space. Soil moisture fields are not continuous but are full of discontinuities caused by many factors, including: strong precipitation gradients, snowfall redistribution, topographical divides, slope-aspect, land-use, differences in soil hydraulic properties, fluvial/aeolian deposition, human intervention (irrigation, drainage, flooding), and vegetation cover. The existence of discontinuities in soil moisture fields and their temporal variability make it difficult to use statistical interpolation techniques based on a limited number of point measurements for the generation of high resolution soil moisture maps. Accurate predictions of regional soil moisture distributions require direct remote sensing observations that capture discontinuities in soil moisture fields.

Near real time information on the spatial distribution of soil moisture will result in (i) significant improvements in battlefield decision making capabilities for mobility and trafficability modeling ${ }^{[21,22]}$, (ii) improved prediction of

\footnotetext{
${ }^{1}$ Jan_Hendrickx_NMT@msn.com; phone: 575-835-5892; 801 LeRoy Place, NMT/MSEC 240, Socorro NM 87801.
} 
performance of landmine and IED sensors ${ }^{[4,10,23,24]}$ as well as of other electromagnetic and thermal sensors employed by the Army, and (iii) greatly improved assimilation of soil moisture data at different scales into hydrologic models for the prediction of watershed responses and flooding ${ }^{[25]}$. Building on earlier soil moisture mapping research by our team ${ }^{[26,27]}$ using Landsat imagery at $30 \mathrm{~m}$ resolution, the objective of this study is to describe a novel method for soil moisture mapping at $2.7 \mathrm{~m}$ scale by downscaling the Landsat soil moisture product using QuickBird optical imagery with pixel size of $2.7 \mathrm{~m}$.

\section{ERDC COUNTERMINE SIMULATION TESTBED}

The ERDC Countermine Simulation Testbed is a high-resolution (cm's) virtual testing capability for the evaluation of the performance of infrared sensors in complex natural and man-made environments. Such environments may contain irregular ground surfaces, multiple soil types, surface vegetation, roads, and exposed and buried rocks and other objects $^{[28]}$. The Countermine Simulation Testbed integrates a soil model, a vegetation model, and a ray-casting model to achieve a faithful representation of all processes that significantly affect an infrared sensor image. A key component of the energy balance is heat emitted or absorbed by the soil. For imagery, only the behavior at the surface of the scene is of interest. But, heat transport must be modeled in three dimensions to capture the surface expression of subsurface heat transport processes. The thermal properties of a soil depend on its moisture content, requiring that hydrologic processes be simulated as well. Moisture and thermal energy movement in the soil are computed with the ADH (Adaptive Hydraulics/Hydrology Model) ${ }^{[29]}$. ADH is a spatially adaptive, continuous Galerkin, finite element model that simulates partially-saturated flow and heat transport in three-dimensional soils (or other materials), coupled to two-dimensional surface water flow on a face of the soil ${ }^{[30]}$. The vegetation model simulates infrared absorption, reflection, and transmission by discretized plant leaves and stems. Ray casting provides boundary conditions for the soil and vegetation thermal models, and produces multispectral images of energy reflected and emitted from the synthetic scene. Calculations to date include a multi-million-element simulation for an arid test site that is only a few meters in its longest dimension (Figure 1). The models are driven with meteorological data and are built using material property data collected at the field site. Synthetic images produced are compared against those from thermal cameras (Figure 2). A long-term goal of this work is to help build inversion software to estimate ground state information (soil moisture and physical property distributions) from airborne and satellite imagery.

The Simulation Testbed produces realistic synthetic images that match field-collected images both in resolution and complexity. Moreover, quantitative comparison of the magnitude and variation of intensities in synthetic and fieldcollected images is encouraging. The simulated imagery is helping predict sensor performance under a variety of weather and vegetation conditions, thereby providing guidance on optimal times-of-day and conditions to see contrast in the images ${ }^{[29]}$. Validation studies to date have shown that the Countermine Simulation Testbed produces realistic simulations at sites where ground measurements are available such as in the arid regions of the southwestern USA. The purpose of this study is to develop a method for meter scale soil moisture retrieval for the Simulation Testbed at sites where no ground measurements are available such as Helmand Province in southern Afghanistan.

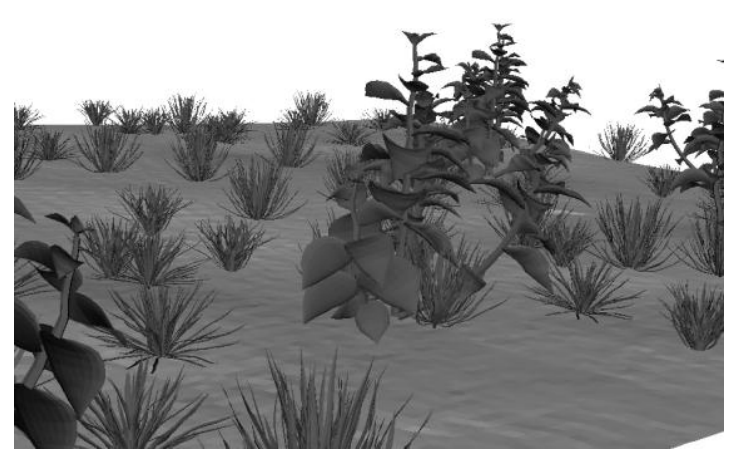

Figure 1. Synthetic scene showing the ground surface and both large desert plants and grasses ${ }^{[28]}$.
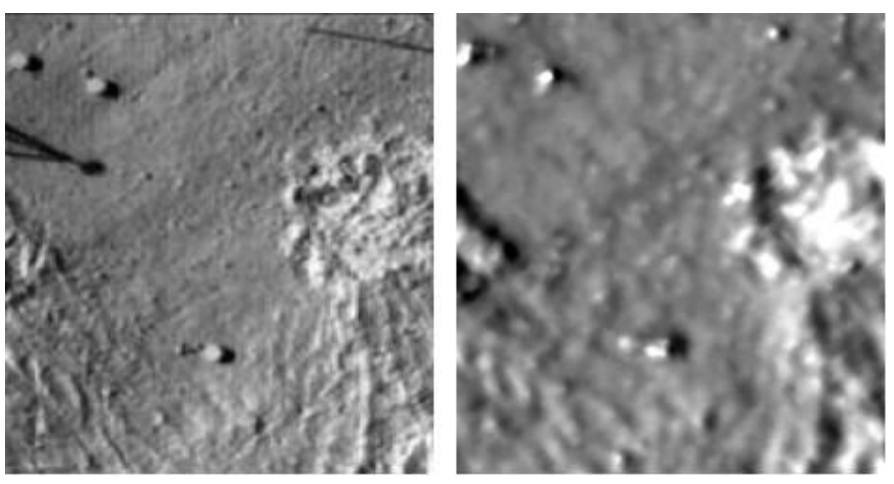

Figure 2. Image from a mid-wave IR camera (left) and a simulated image of physical temperatures (right) ${ }^{[28]}$. 


\section{EVAPORATIVE FRACTION METHOD FOR SOIL MOISTURE MAPPING}

The evaporative fraction method is based on the long-known relationship between root zone soil moisture and the partition of incoming short and long-wave radiation between sensible and latent heat fluxes ${ }^{\text {[31-34] }}$. The method became feasible only recently after development and validation of algorithms to derive reliable estimates of the fluxes of the energy balance from remotely sensed optical and thermal imagery ${ }^{[26,35-42]}$.

In many agro-hydrological studies root zone soil moisture is used to reduce potential evapotranspiration to actual evapotranspiration ${ }^{[43-47]}$. When the soil is wet, most of the available energy (net radiation minus soil heat flux) is used for evapotranspiration or latent heat flux $(\lambda E)$ and almost no energy is left for sensible heat flux $(H)$. When the soil is dry, most of the available energy is used to heat the soil so that latent heat flux (evapotranspiration) becomes small. One way to express this partitioning of radiant energy is the evaporative fraction $(\Lambda)$ that is defined as the latent heat flux divided by the net available energy ${ }^{[48,49]}$. The net available energy equals net radiation $\left(R_{n}\right)$ minus the soil heat flux $(G)$.

$$
\Lambda=\frac{\lambda E}{\lambda E+H}=\frac{\lambda E}{R_{n}-G}
$$

The energy partitioning calculated with the evaporative fraction is primarily related to the soil moisture content ${ }^{[50]}$. Using in situ root zone soil moisture measurements and validated evaporative fraction data from the Surface Energy Balance for Algorithm for Land (SEBAL) obtained during field experiments in Kansas and Spain, the following empirical relationship was determined ${ }^{[37]}$ :

$$
S=\frac{\theta}{\theta_{\text {sat }}}=e^{\frac{\Lambda-1}{0.42}}
$$

where $S$ is degree of saturation, $\theta$ is volumetric water content, and $\theta_{\mathrm{s}}$ is volumetric water content at saturation. Eq. [2] was derived from soil moisture measurements obtained on grazed and un-grazed grassland in Kansas on alluvial soils and loess ${ }^{[51]}$ as well as from rainfed (vineyard, barley, wheat) and irrigated crops (maize, alfalfa) in Central Spain on sandy loams ${ }^{[36,52]}$. Using evaporative fraction $(\Lambda)$ estimates obtained from the remote sensing algorithms Surface Energy Balance Algorithms for Land (SEBAL) $)^{[42]}$ or Mapping EvapoTranspiration at High Resolution with Internalized Calibration (METRIC) ${ }^{[53]}$ Eq. [2] can be used to obtain estimates of degree of saturation $(S)$ in the root zone from optical satellite imagery such as Landsat and MODIS.

A validation of Eq. [2] was conducted using soil moisture data from irrigated fields in Pakistan and Mexico. Equation [2] predicted soil moisture with a root mean square error of $0.05 \mathrm{~cm}^{3} \mathrm{~cm}^{-3}$; the error is less than $0.07 \mathrm{~cm}^{3} \mathrm{~cm}^{-3}$ in $90 \%$ of cases. Given the wide range of conditions used to derive and to validate Eq. [2] it was concluded that Eq. [2] is minimally affected by vegetation type or soil type and may have general applicability ${ }^{[35]}$.

Figure 3 presents a Landsat7 image covering a typical area of approximately $16 \times 12 \mathrm{~km}$ in Helmand Province (Afghanistan) on April 23, 2009. This area is taken from the center of a Landsat7 image (Path 155, Row 38) that doesn't contain any stripes. The pixel size is $30 \times 30 \mathrm{~m}$. This image is converted into a soil moisture map by first calculating the latent and sensible heat fluxes using METRIC and then the degree of soil moisture saturation using Eq. [2] (Figure 4). Similar soil moisture maps have been validated quantitatively ${ }^{[35,37,54]}$ as well as qualitatively ${ }^{[26,27]}$.

\section{DOWNSCALING LANDSAT SCALE SOIL MOISTURE MAP USING QUICKBIRD IMAGE}

The soil moisture map in Fig. 4 has a spatial resolution of $30 \mathrm{~m}$ that is often too coarse for the initialization of the Countermine Simulation Testbed since the typical dimension of an IED will be on the order of one meter or less. Therefore, it is necessary to downscale the Landsat soil moisture map. In this section we propose a method to do this using an optical image from Quickbird. A Landsat image has 3 visual bands (1, 2, and 3), one near-infrared band (4), two mid-infrared bands $(5,7)$ and one thermal infrared band (6). All these bands are needed to implement METRIC for evaluation of the evaporative fraction and soil moisture using energy balance physics. Of special importance is the thermal band 6 since without it METRIC cannot be employed. QuickBird has only four bands: three visual (1, 2, 3) and one near-infrared (4). Since QuickBird has no thermal infra-red band it is impossible to derive a soil moisture map from QuickBird imagery using METRIC. Instead we have to find a relationship between the four bands of QuickBird and the Landsat determined soil moisture for each pixel. 


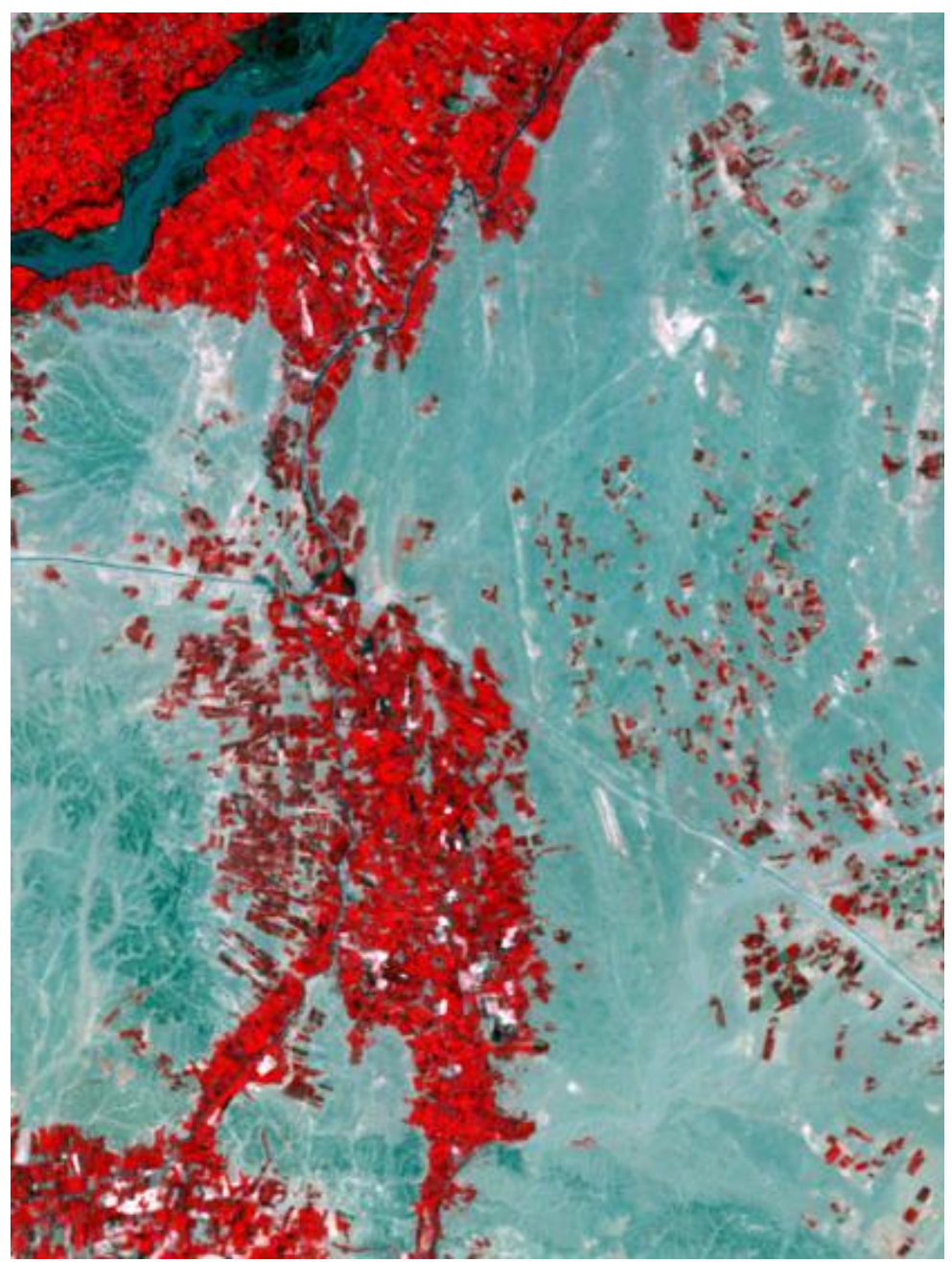

Figure 3. Landsat7 Image on April 23, 2009, in false colors Vegetation is colored red. Spatial resolution is $30 \mathrm{~m}$ pixel size. Image area is about $16 \times 12 \mathrm{~km}$.

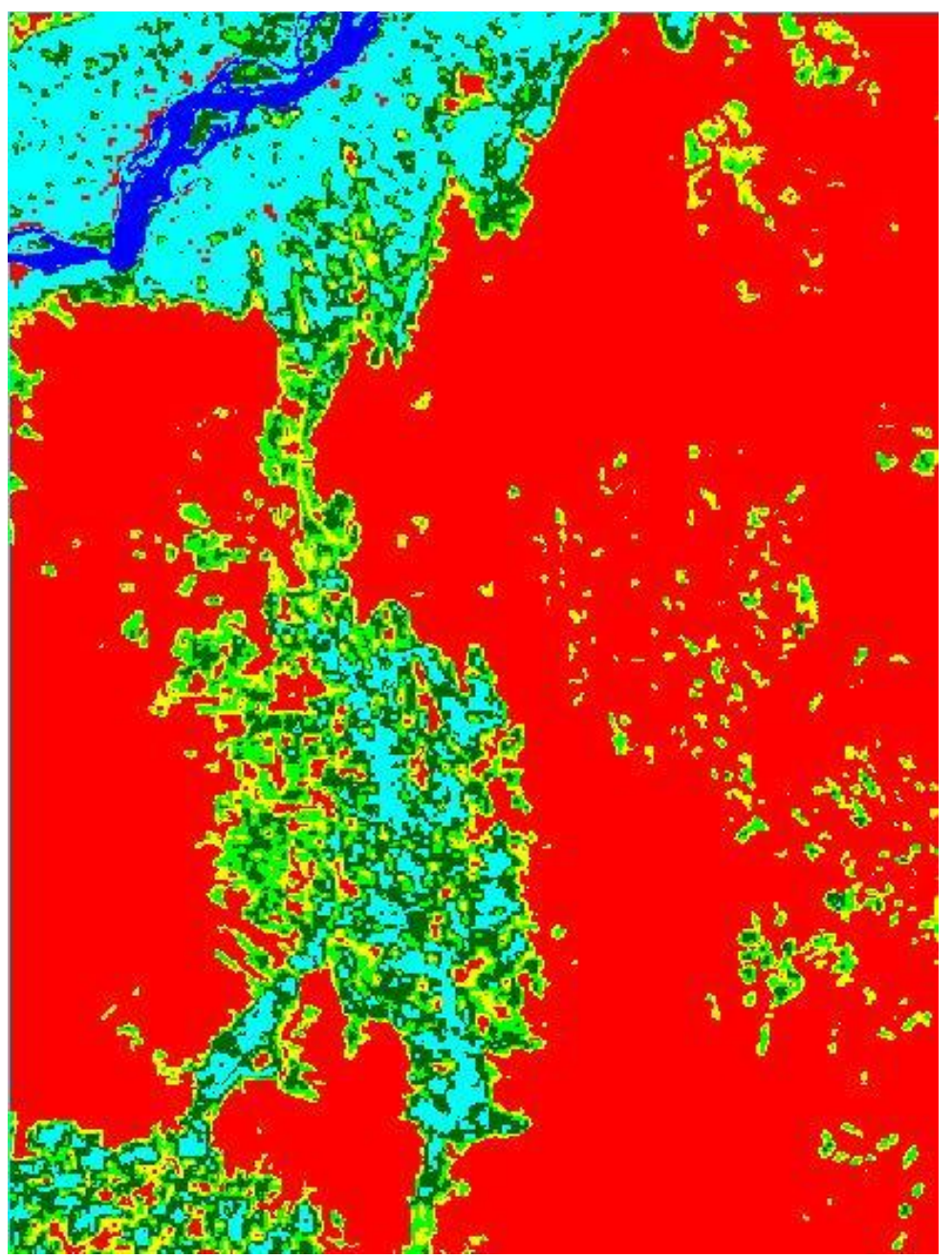

Figure 4. Landsat7 Soil Moisture Map on April 23, 2009. Spatial resolution is $30 \mathrm{~m}$ pixel size. Image area is about $16 \times 12 \mathrm{~km}$. Soil moisture expressed as degree of soil saturation: 0.0-0.2 red; 0.2-0.4 yellow; 0.4-0.6 light green; 0.6-0.8 green; 0.8-1.0 light blue. Water is colored blue. 
Since the wavelengths of the first four bands of Landsat are identical to those of the four bands of QuickBird we first tested whether it is possible to predict Landsat soil moisture (Fig. 4) from the digital values of Landsat bands 1, 2, 3, and 4. If this would not be possible, there is no hope to use the four similar bands of QuickBird for the prediction of soil moisture. Fortunately, a significant regression was found between the digital values of Landsat bands 1, 2, 3, and 4 of Landsat and Landsat soil moisture (SM). This regression equation was then used to predict Landsat soil moisture (PSM) from the digital values of Landsat bands 1, 2, 3, and 4. Figure 5 shows the significant relationship between the original Landsat soil moisture (SM) and the predicted Landsat soil moisture (PSM) that is "prove of concept" that soil moisture indeed can be predicted from the digital values of Landsat bands 1, 2, 3, and 4 and, therefore, most likely also from the digital values of bands 1, 2, 3, and 4 of QuickBird imagery.

This hypothesis was tested using a Quickbird image (Fig. 6) of April 24, 2009, covering the same area as the Landsat image in Fig. 3. Since the images are only one day apart, soil moisture conditions will be the same except perhaps for a few fields that received irrigation water between Landsat and Quickbird overpasses. The Quickbird image was converted into a soil moisture map with pixel size $2.7 \mathrm{~m}$ using the regression equation previously derived between the digital values of Landsat bands 1, 2, 3, and 4 and Landsat soil moisture (Fig. 7). This regression equation is very preliminary and, therefore, will not be presented in this study that only aims to "prove the concept". In addition, the regression coefficients might well change substantially under different weather conditions, during a different season of the year, or in a different region of the country.

The final step is to plot and to regress the Quickbird predicted soil moisture (PSM) against the Landsat soil moisture (SM) (Fig. 8). There is a significant correlation between these two variables but the spread of the data points is larger than the one seen in Fig. 5 because the support of the variables is about one order of magnitude different (30 m for the Landsat soil moisture and $2.7 \mathrm{~m}$ for bands 1, 2, 3, and 4 of QuickBird). Sometimes Landsat soil moisture is low while a few QuickBird pixels have high soil moisture values; this could be explained by a small vegetable garden on the order of $10 \times 10 \mathrm{~m}$ in the otherwise dry desert. Sometimes Landsat soil moisture is high while a few QuickBird pixels have low soil moisture values; this could be explained by a small area for a homestead or farming operations in the middle of moist irrigated fields. So, these anomalies are real and show up as outliers in Fig. 8 because the support of the regressed variables is not equal. The total number of pixels in the graph is about 33,000 and most of these are located in the solid green area so that the percentage of outliers is relatively small.

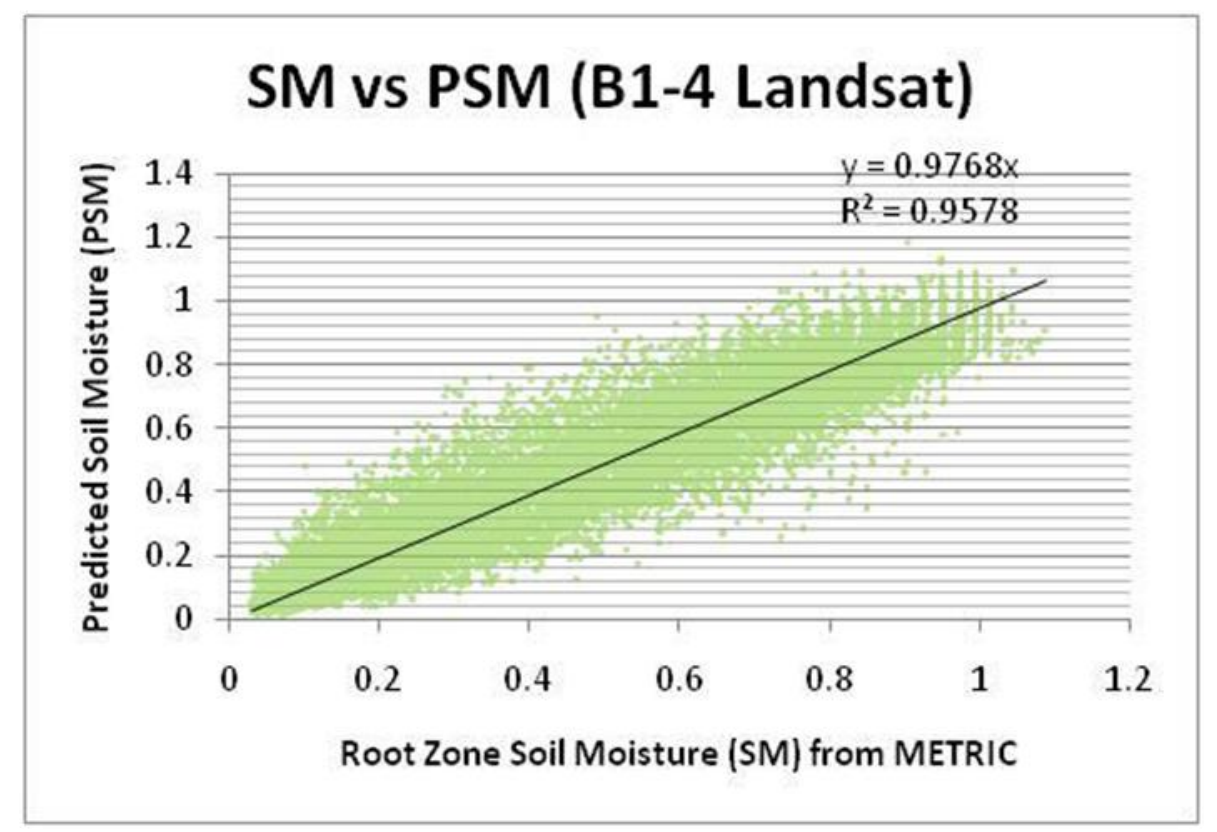

Figure 5. Regression between Landsat Soil Moisture (SM) from METRIC and its prediction (PSM) using Landsat bands 1-4. 


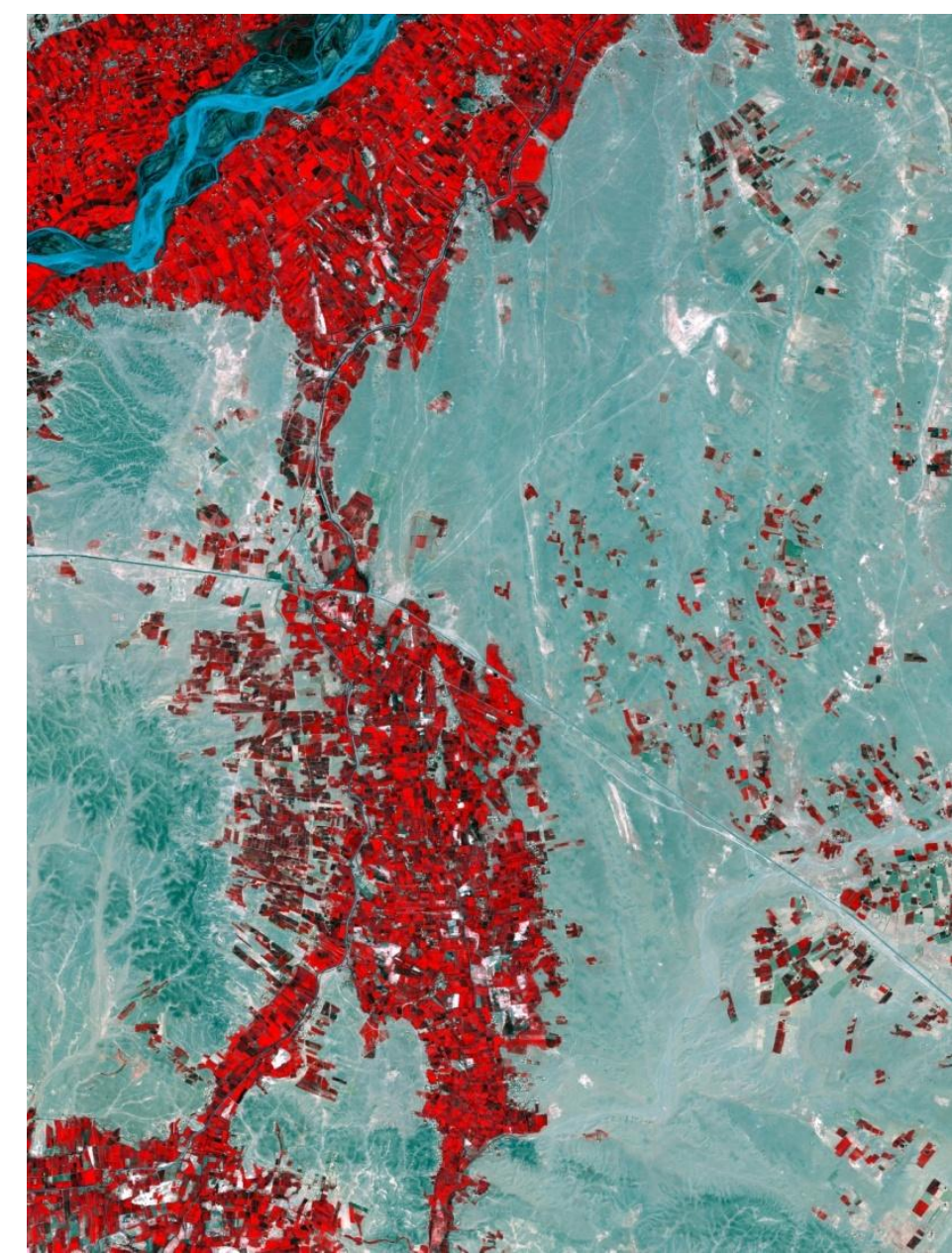

Figure 6. Quickbird Image on April 24, 2009, in false colors. Vegetation is colored red. Spatial resolution is $2.7 \mathrm{~m}$ pixel size. Image area is about $16 \times 12$ $\mathrm{km}$.

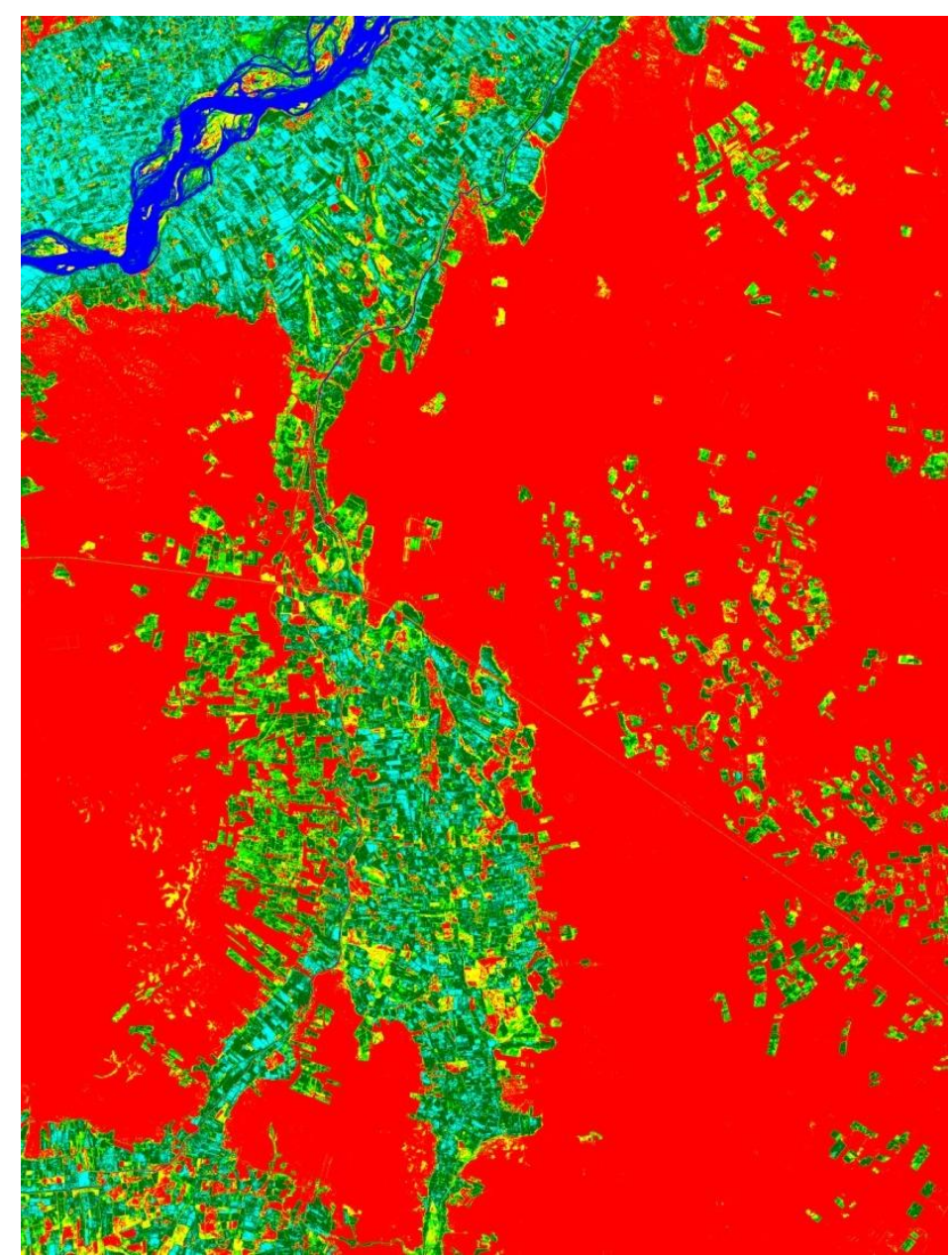

Figure 7. Quickbird Soil Moisture Map on April 24, 2009. Spatial resolution is $2.7 \mathrm{~m}$ pixel size. Image area is about $16 \times 12 \mathrm{~km}$. Soil moisture expressed as degree of soil saturation: 0.0-0.2 red; 0.2-0.4 yellow; 0.4-0.6 light green; 0.60.8 green; 0.8-1.0 light blue. Water is colored blue. 


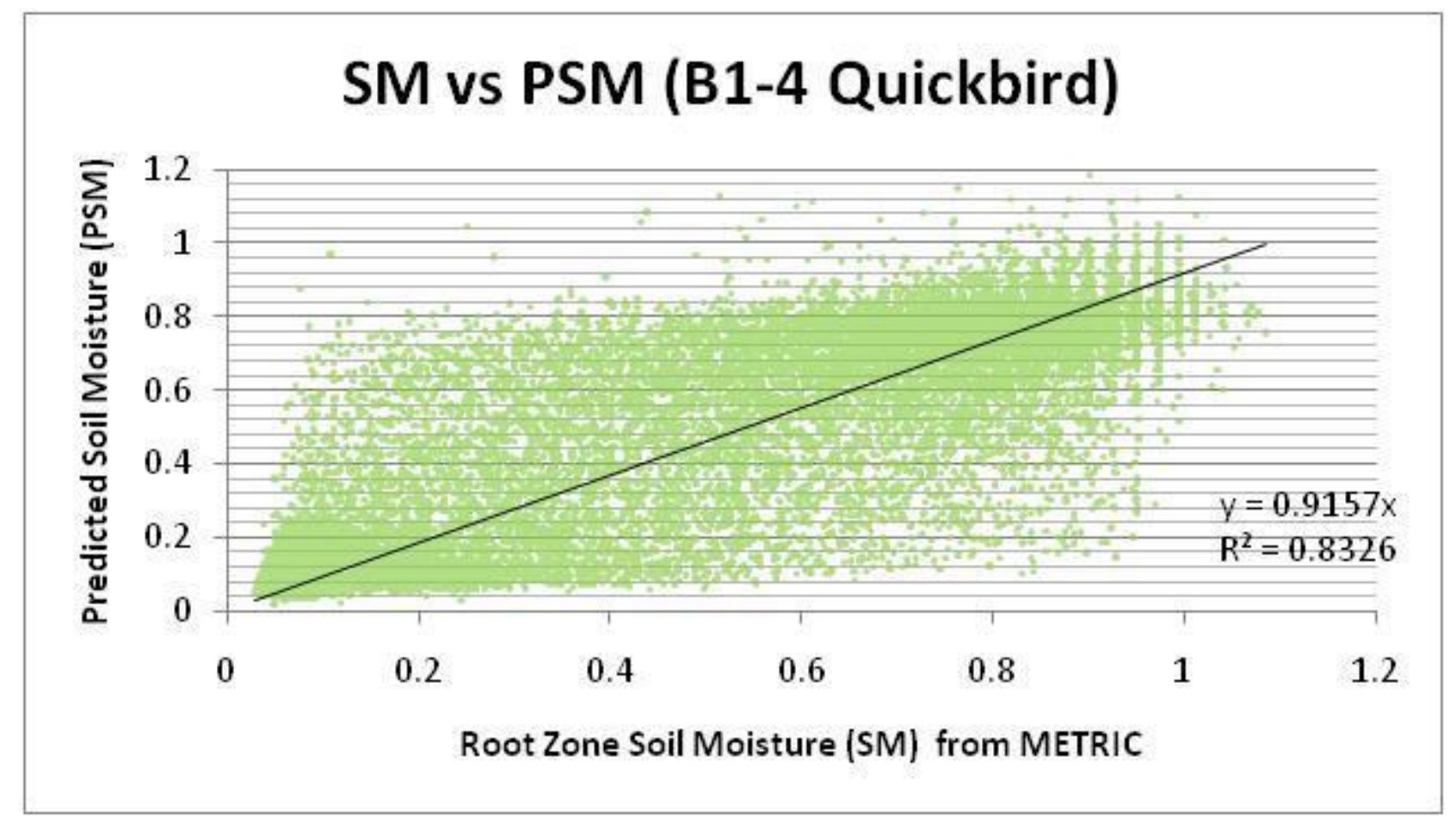

Figure 8. Regression between Landsat Soil Moisture (SM) at $30 \mathrm{~m}$ resolution from METRIC and its prediction (PSM) using bands 1-4 of QuickBird at 2.7 m resolution.

\section{INSPECTION OF QUICKBIRD SCALE SOIL MOISTURE MAP}

A strong correlation and significant regression does exist between the METRIC Landsat scale soil moisture map and the downscaled Quickbird soil moisture map (Fig. 8) but due to differences in pixel sizes between Landsat (30 m) and Quickbird $(2.7 \mathrm{~m})$ the downscaled Quickbird soil moisture maps contain imperfections. Therefore, two small areas of about $3 \times 3 \mathrm{~km}$ will be closely inspected to see how the downscaled Quickbird soil moisture map compares with the physically based Landsat soil moisture map.

The first area covers contiguous irrigated fields interspersed with almost bare dry lands; important features for our inspection are an asphalt road going from East to West and an irrigation canal winding from the South to the North. Figures 9 and 10 show the area in false colors (vegetation is red) at, respectively, the Landsat $(30 \mathrm{~m})$ and Quickbird scale $(2.7 \mathrm{~m})$. Whereas the Landsat image very well represents the overall land surface features such as irrigated field and bare soils, its blurriness misses many details visible on the Quickbird image. The Landsat image definitively picks up signatures of the apshalt road and the irrigation canal but without any ground information one couldn't tell that these signatures represent a road and a canal. The Quickbird image contains many details and provides a detailed map depicting all landscape features with great detail: roads, canals, houses and compounds, irrigated fields, and dry lands. However, it cannot give direct information about soil moisture conditions other than that a vegetated field and a bare soil most likely are, respectively, moist and dry. The Landsat soil moisture image (Fig.11) presents this information as does the downscaled Quickbird soil moisture image (Fig. 12). Comparing these two soil moisture images indicates that there generally is good agreement: the irrigated fields are moist while the bare lands are dry. However, there are also mismatches between the Landsat and Quickbird soil moisture maps. If a mismatch is consistent over an area larger than $30 \times 30 \mathrm{~m}$, the Quickbird soil moisture map is in error since the Landsat soil moisture map is based on environmental physics and the Quickbird one on a statistical regression. For example, directly above symbol A (Fig. 10) we observe a few irrigated fields and a darker colored field just to their right. Is this darker colored field moist or dry? Both the Landsat and Quickbird soil moisture maps (Figs. 11 and 12) indicate this field is dry and we conclude it is dry. Directly above and to the right of symbol $\mathbf{B}$ we observe two 
darker colored fields that cover several Landsat pixels (Fig. 9). These fields have a degree of saturation 0.0-0.2 on the Landsat soil moisture map (Fig. 11) but 0.2-0.4 on the Quickbird soil moisture map (Fig. 12). Also, the black asphalt road shows up on the Quickbird soil moisture map with a degree of saturation 0.2-0.4 that clearly is impossible for a road surface during a dry period. We conclude that the Quickbird soil moisture product tends to "moisten" dark objects. Darker colored soils generally are wetter than lighter colored soils but not always since dark dry soils do exist. For example, in our location we observe a dark apshalt road that definitively is not moist but dry. The Landsat soil moisture map picks these differences up since it also use the surface temperature to derive the soil moisture status of a pixel. The Quickbird soil moisture map is based on a regression using its visual and nearinfrared reflectances but no surface temperatures. Nevertheless, the regression (Fig. 8) is highly significant and does generally produce good results in the area under consideration. For example, directly above symbol $\mathbf{C}$ we observe dark colored fields that have a degree of saturation 0.4-0.6 on both the Landsat and Quickbird soil moisture maps (Figs. 11 and 12). These bare fields have just received a pre-planting irrigation and are moist.

The second area covers again contiguous irrigated field crossed by a wide river with sandbanks. The Landsat and Quickbird images as well as their respective soil moisture maps are presented in Figs. 13-16. As observed in the first area there exists generally good agreement between the Landsat and Quickbird soil moisture maps in the irrigated areas. However, on the sandbanks the two soil moisture maps differ greatly. While the degrees of saturation of the Landsat soil moisture map on the sandbars (Fig. 15) vary between 0.4-1.0, the Quickbird soil moisture map (Fig. 16) contains values between 0.0-0.6. This is a large difference and indicates that the Quickbird soil moisture values for the sandbars are not correct. On the sandbars the soils are highly reflective which drives the Quickbird soil moisture estimate down while on the asphalt road the black color of the asphalt (low reflectivity) drives the soil moisture estimate up.

Overall the QuickBird soil moisture map seems quite reliable in areas away from sandbars and asphalt roads because the downscaling regression breaks down for highly reflective sands and dark asphalt roads. Thus, a global approach covering the entire image for the downscaling regression from Landsat to QuickBird scale is not the most optimal. We need to test regressions that are constrained by the true Landsat soil moisture maps either on a pixel by pixel basis or after an unsupervised classification to partition the area in a number of land cover classes that each have their own downscaling regression. This approach seems quite appropriate because recent work by the three senior authors has shown that the use of multiple remotely sensed root zone soil moisture images shows great promise for soil boundary delineation ${ }^{[55]}$.

\section{CONCLUSIONS AND FUTURE WORK}

Two major conclusions result from this "proof of concept" study: 1. METRIC derived root zone soil moisture can be predicted from reflectance of the three visual and one near-infrared band of Landsat and Quickbird operational and optical satellite images; 2 . Due to differences in soil types and land covers one regression equation is not sufficient for the reliable estimation of soil moisture over an entire image.

Future work will focus on: 1. Evaluation of the best statistical procedures to predict root zone soil moisture at Quickbird scale from Landsat and Quickbird operational optical satellite images; 2. Field validation of the downscaling approach in the Middle Rio Grande Valley of New Mexico using it as a proxy for Helmand Province in Afghanistan.

\section{ACKNOWLEDGEMENT}

This research is funded by the Coastal and Hydraulics Laboratory, Engineer Research and Development Center of the U.S. Army Corps of Engineers in Vicksburg, MS. The STIR grant was managed through the Army Research Office. The Quickbird imagery was kindly provided by the Army Geospatial Center, Engineer Research and Development Center of the U.S. Army Corps of Engineers in Fort Belvoir, VA. 


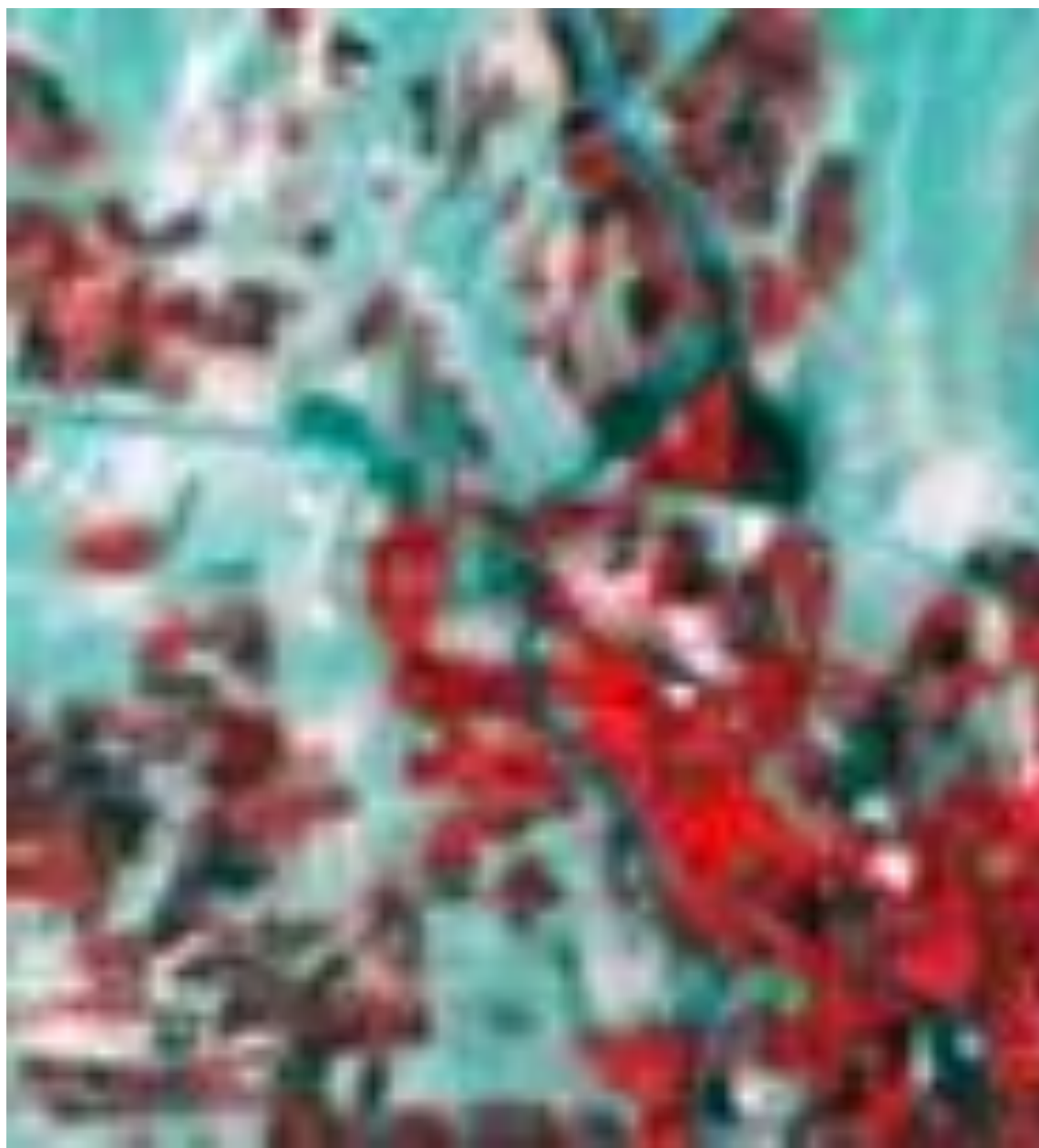

Figure 9. Section B: Landsat7 Image on April 23, 2009. Spatial resolution is $30 \mathrm{~m}$ pixel size. Image area is about $3 \times 3 \mathrm{~km}$.

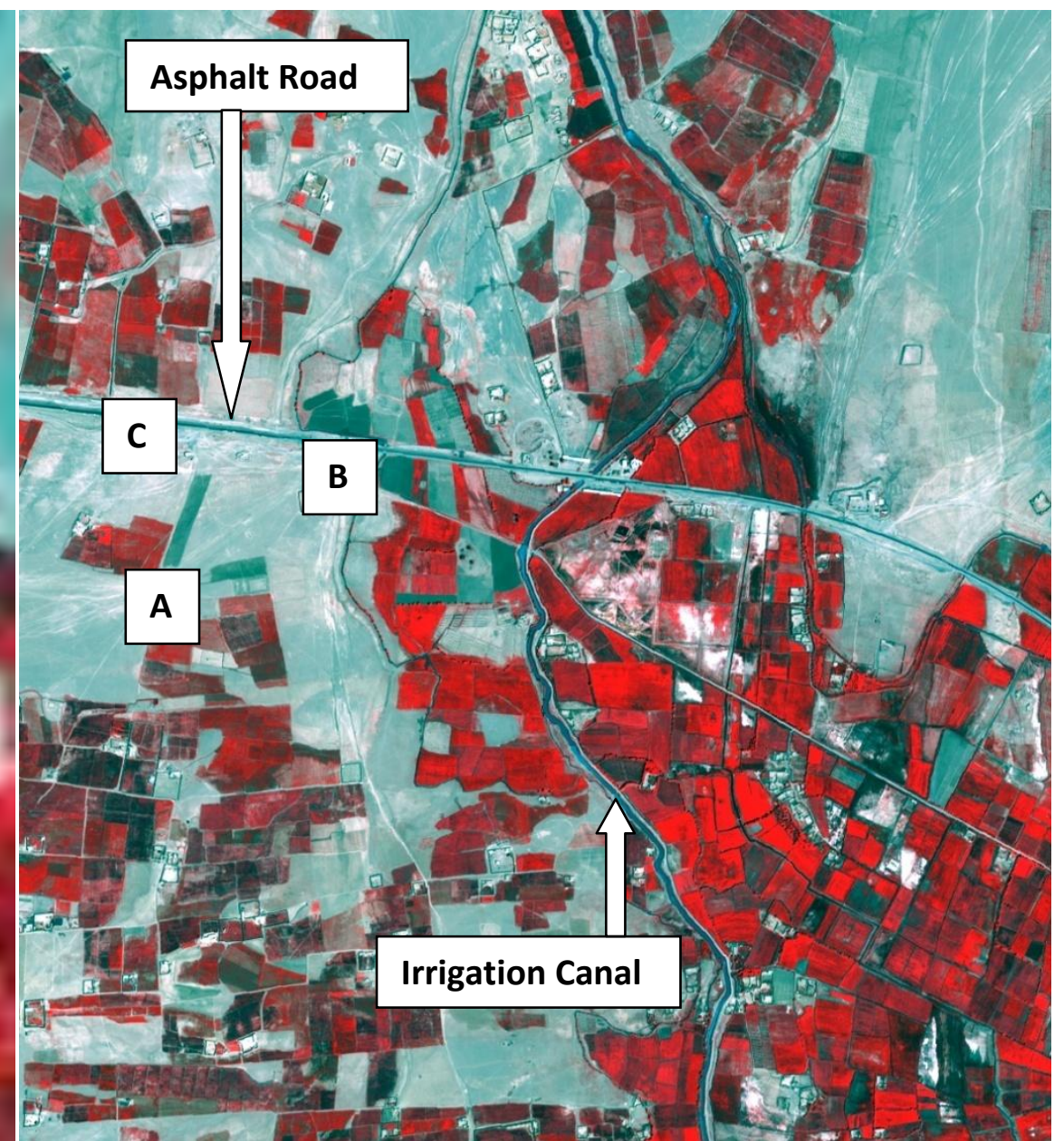

Figure 10. Section B: Quickbird Image on April 24, 2009. Spatial resolution is $2.7 \mathrm{~m}$ pixel size. Image area is about $3 \times 3 \mathrm{~km}$. 


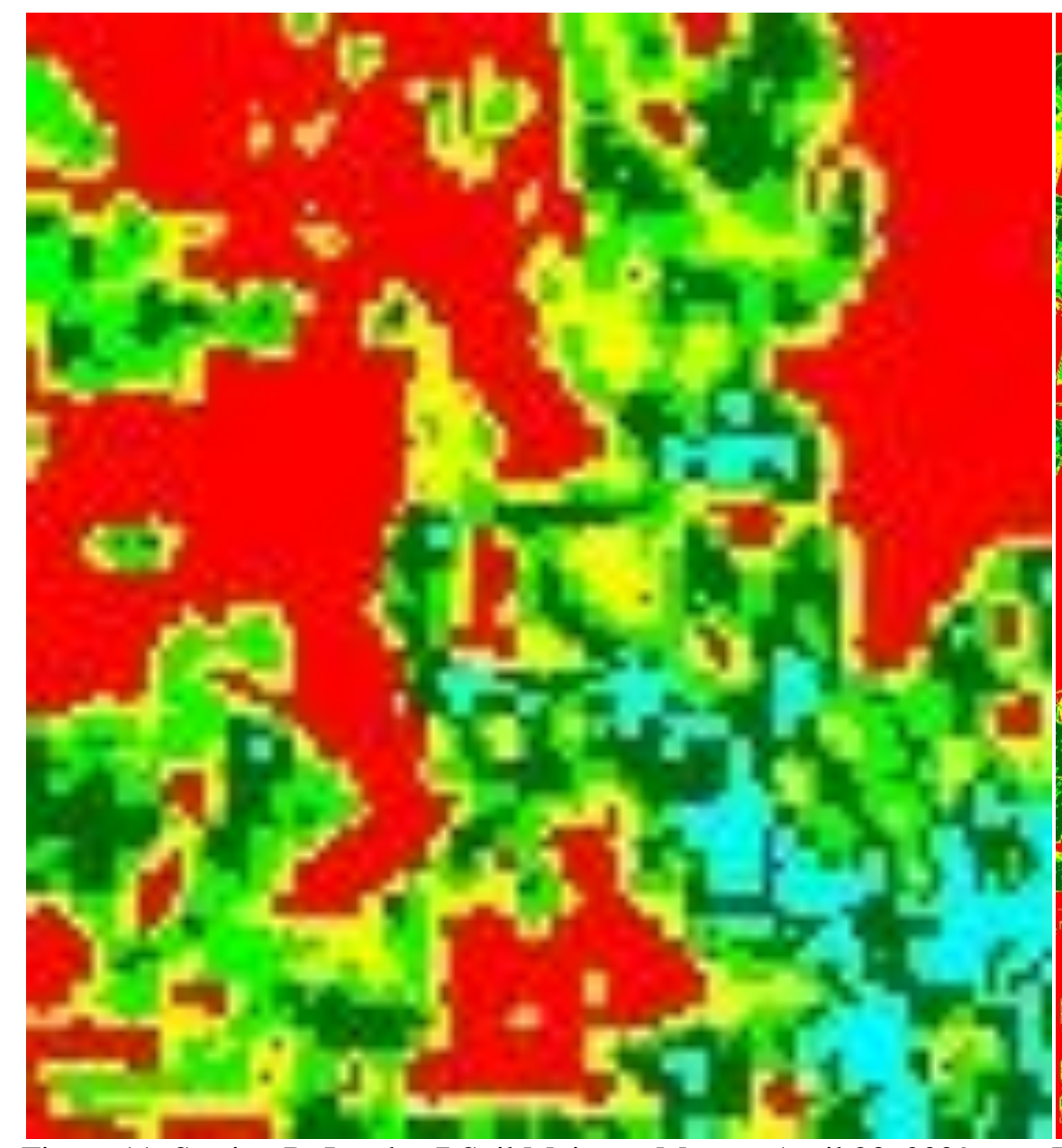

Figure 11. Section B: Landsat7 Soil Moisture Map on April 23, 2009.

Spatial resolution is $30 \mathrm{~m}$ pixel size. Image area is about $3 \times 3 \mathrm{~km}$.

$0.0-0.2$ 0.2-0.4

Color

ra

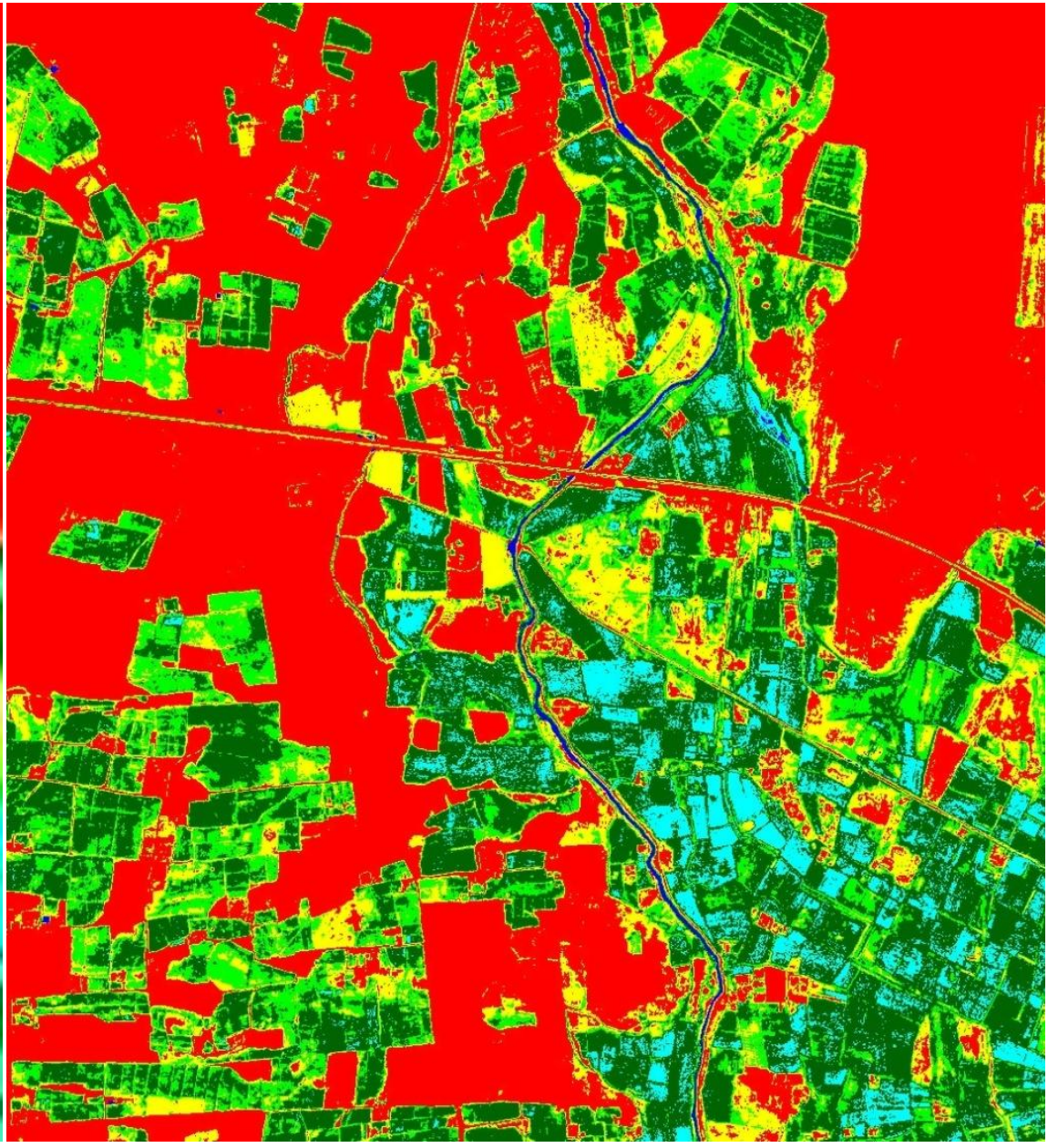

Figure 12. Section B: Quickbird Soil Moisture Map on April 24, 2009.

Spatial resolution is $2.7 \mathrm{~m}$ pixel size. Image area is about $3 \times 3 \mathrm{~km}$. 


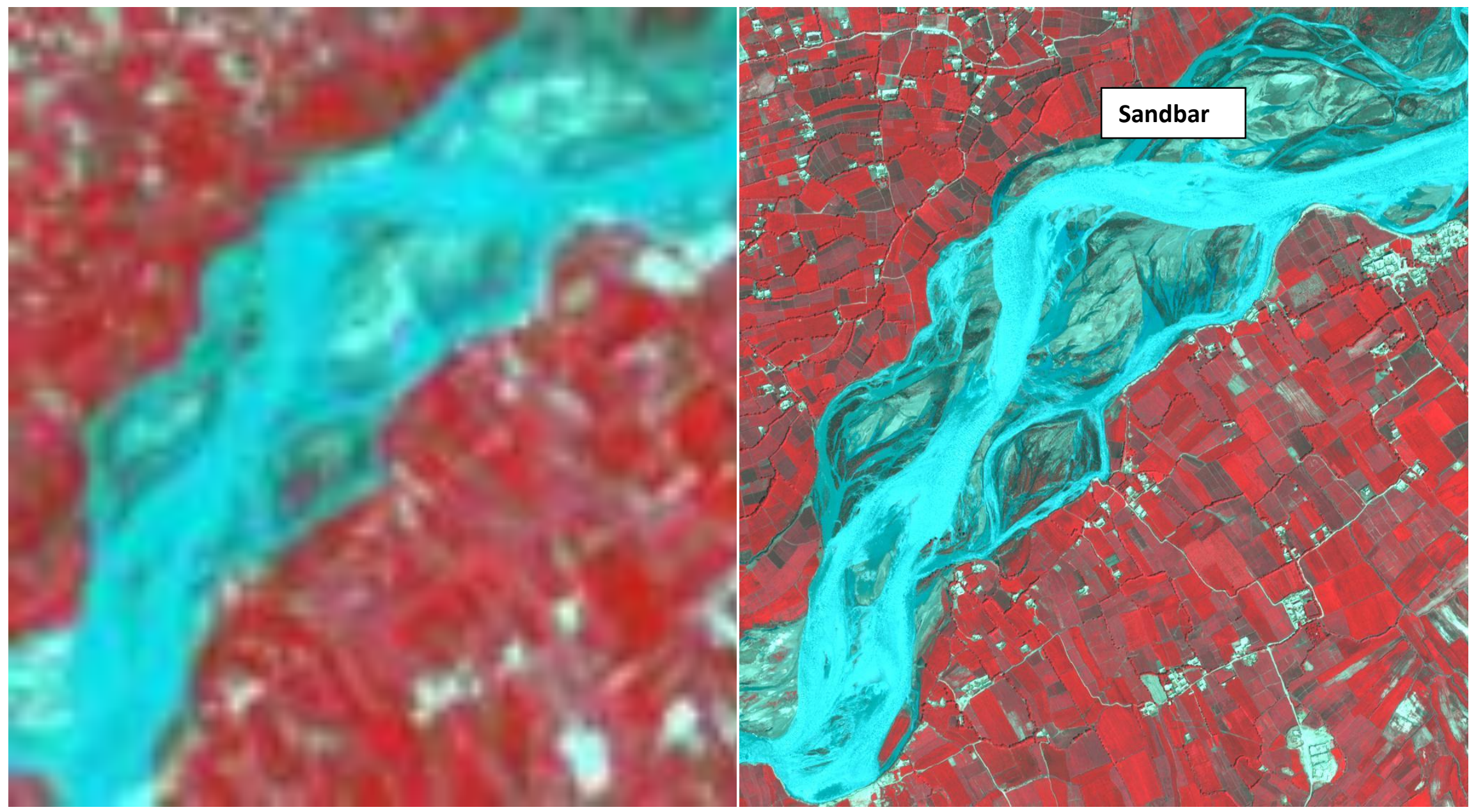

Figure 13. Section A: Landsat7 Image on April 23, 2009. Spatial resolution is $30 \mathrm{~m}$ pixel size. Image area is about $3 \times 3 \mathrm{~km}$.
Figure 14. Section A: Quickbird Image on April 24, 2009. Spatial resolution is $2.7 \mathrm{~m}$ pixel size. Image area is about $3 \times 3 \mathrm{~km}$. 

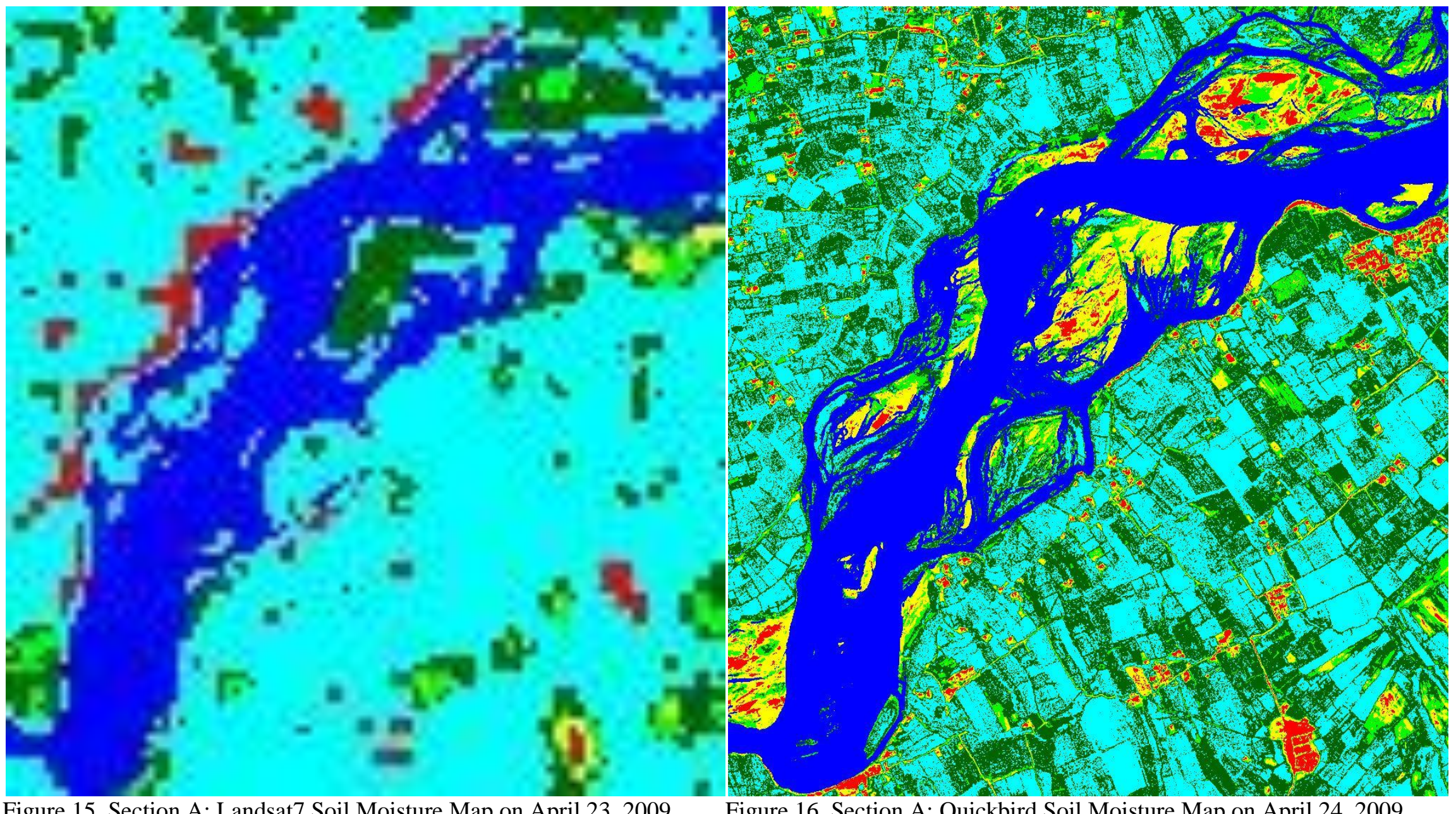

Figure 15. Section A: Landsat7 Soil Moisture Map on April 23, 2009.

Spatial resolution is $30 \mathrm{~m}$ pixel size. Image area is about $3 \times 3 \mathrm{~km}$

Figure 16. Section A: Quickbird Soil Moisture Map on April 24, 2009.

Saturation Ratio $0.0-0.2$ $0.2-0.4$

$0.4-0.6$

Spatial resolution is $2.7 \mathrm{~m}$ pixel size. Image area is about $3 \times 3 \mathrm{~km}$.

Color

$0.6-0.8$

$0.8-1.0$

Open Water 


\section{REFERENCES}

1. Lessem, A., G. Mason, and R. Ahlvin, Stochastic vehicle mobility forecasts using the NATO reference mobility model. Journal of Terramechanics, 1996. 33(6): p. 273-280.

2. Van Dam, R.L., et al., Environmental effects on landmines and UXO detection sensors. Fast Times, 2005. 10(1): p. 36.

3. Van Dam, R.L., B. Borchers, and J.M.H. Hendrickx, Soil effects on thermal signatures of buried nonmetallic landmines. Proc. International Society for Optical Engineering, SPIE, 2003. 5089: p. 1210-1218.

4. Miller, T.W., J.M.H. Hendrickx, and B. Borchers, Radar detection of buried landmines in field soils. Vadose Zone J, 2004. 3: p. 11161127.

5. Miller, T.W., et al., Effect of soil moisture on land mine detection using ground penetrating radar. Proc. International Society for Optical Engineering, SPIE, 2002. 4742: p. 281-290.

6. Hong, S.-H., et al., Land mine detection in bare soils using thermal infrared sensors. Proc. International Society for Optical Engineering, SPIE, 2002. 4742: p. 43-50.

7. Hong, S.-H., et al., Impact of soil water content on landmine detection using radar and thermal infrared sensors. Proc. International Society for Optical Engineering, SPIE, 2001. 4394: p. 409-416.

8. Das, B.S., J.M.H. Hendrickx, and B. Borchers, Modeling transient water distributions around landmines in bare soils. Soil Science, 2001. 166(3): p. 163-173.

9. Borchers, B., et al., Enhancing dielectric contrast between land mines and the soil environment by watering: modeling, design, and experimental results. Proc. International Society for Optical Engineering, SPIE, 2000. 4038(2): p. 993-1000.

10. Hendrickx, J.M.H., et al., Worldwide distribution of soil dielectric and thermal properties. Proc. International Society for Optical Engineering, SPIE, 2003. 5089: p. 1158-1168.

11. Niedzialek, J.M. and F.L. Ogden, Numerical investigation of saturated source area behavior at the small catchment scale. Adv. Water Resour., 2004. 27: p. 925-936.

12. Downer, C.W., et al., Theory, development, and applicability of the surface water hydrologic model CASC2D. Hydrological Processes, 2002. 16(2): p. 255-275.

13. Senarath, S.U.S., et al., On the calibration and verification of distributed, physically-based, continouous, Hortonian hydrologic models. Water Resour. Res., 2000 36(6): p. 1495-1510.

14. Downer, C.W. and F.L. Ogden, Users Manual: Gridded Surface/Subsurface Hydrologic Analysis, in Engineering Research and Development Center Technical Report. 2003, U.S. Army Corps of Engineers.

15. Downer, C.W. and F.L. Ogden, GSSHA: A model for simulating diverse streamflow generating processes. J. Hydrol. Engrg., 2004. 9: p. 161-174.

16. Dingman, S.L., Physical Hydrology. 2002, Upper Saddle River, New Jersey 07458: Prentice Hall. 646.

17. Ogden, F.L., et al., Hydrologic analysis of the Fort Collins, Colorado, flash flood of 1997. J. Hydrology, 2000. 228: p. 82-100.

18. Shukla, J. and Y. Mintz, Influence of land surface evapotranspiration on the earth's climate. Science, 1982. 215:: p. 1498-1501.

19. Milly, P.C.D. and K.A. Dunne, Sensitivity of the global water cycle to the water-holding capacity of land. J. Climate, 1994. 7: p. 506526.

20. Van de Hurk, B.J.J.M., W.G.M. Bastiaanssen, H. Pelgrum, and E. van Meijgaard, A new methodology for assimilation of initial soil moisture fields in weather prediction models using Meteosat and NOAA data. Journal of Applied Meteorology, 1997. 36: p. 12711283.

21. McWilliams, G. Preparing for NPOESS: a new era of environmental satellite data. 2003 October 16, 2005 [cited; Available from: http://www.nrlmry.navy.mil/BACIMO/2003/proceedings/4-07\%20McWilliams.doc. McWilliams, G., et al., Analysis of the enhanced tactical utility of NPOESS soil moisture data using combat simulations - Draft. 2003, Adelphi, MD 20783: Army Research Laboratory. 55.

23. Van Dam, R.L., B. Borchers, and J.M.H. Hendrickx, Strength of landmine signatures under different soil conditions: implications for sensor fusion. International Journal of Systems Science, 2005. 36(9): p. 573-588 DOI: 10.1080/00207720500147800

24. Hendrickx, J.M.H., et al., Soil effects on ground penetrating radar (GPR) detection of buried non-metallic mines., in Ground Penetrating Radar: Applications in Sedimentology, C.S. Bristow and H.M. Jol, Editors. 2003, Geological Society: London, U.K. p. 191198.

Hendrickx, J.M.H., et al., Improvement of hydrologic model soil moisture predictions using SEBAL evapotranspiration estimates. Proc. International Society for Optical Engineering, SPIE, 2009. 7303: p. 730311.

26. Fleming, K., J.M.H. Hendrickx, and S.-h. Hong, Regional mapping of root zone soil moisture using optical satellite imagery. Proc. International Society for Optical Engineering, SPIE, 2005. 5811: p. 159-170.

27. Hendrickx, J.M.H., et al., Mapping energy balance fluxes and root zone soil moisture in the White Volta Basin using optical imagery. Proc. International Society for Optical Engineering, SPIE, 2006. 6239: p. 238-249.

28. Howington, S.E., et al., A Suite of Models for Producing Synthetic, Small-Scale Thermal Imagery of Vegetated Soil Surface, in XVI International Conference on Computational Methods in Water Resources, P.J. Binning, et al., Editors. 2006: Copenhagen, Denmark. Howington, S.E., Soil moisture and heat transport modeling to support simulation of infrared imaging. Abstract., in 8th. World Congress on Computational Mechanics (WCCM8) \& 5th European Congress on Computational Methods in Applied Sciences and Engineeering (ECCOMAS 2008). 2008: Venice, Italy.

30. Howington, S.E., et al., A model to simulate the interaction between groundwater and surface water, in 1999 High-Performance Computing Users Group Meeting. 1999, Washington, DC: DoD HPC Modernization Office: Monterey, CA.

31. Owe, M. and A.A. van de Griend, Daily surface moisture model for large area semi-arid land applications with limited climate data. J. Hydrology, 1990. 121: p. 119-132. 
32. Kustas, W.P., X. Zhan, and T.J. Jackson, Mapping surface energy flux partitioning at large scales with optical and microwave remote sensing data from Washita '92. Water Res. Res., 1999. 35(1): p. 265-277.

33. De Bruin, H.A.R., A model for the Priestley-Taylor parameter alpha. J. Clim. Appl. Meteorol., 1983. 22: p. 572-578.

34. Davies, J.A. and C.D. Allen, Equilibrium, potential and actual evapotranspiration from cropped surfaces in southern Ontario. J. Appl. Meteorol., 1973. 12: p. 649-657.

35. Scott, C.A., W.G.M. Bastiaanssen, and M.-u.-D. Ahmad, Mapping Root Zone Soil Moisture Using Remotely Sensed Optical Imagery. J. Irrig. and Drain. Engrg., 2003. 129(5): p. 326-335.

36. Bastiaanssen, W.G.M., et al., Area-averaged estimates of evaporation, wetness indicators and top soil moisture during two golden days in EFEDA. Agric. For. Meteorol., 1997. 87(2-3): p. 119-137.

37. Ahmad, M.-U.-D. and W.G.M. Bastiaanssen, Retrieving soil moisture storage in the unsaturated zone using satellite imagery and biannual phreatic surface fluctuations. Irrigation and Drainage Systems, 2003. 17(3): p. 141-161 doi:10.1023/A:1025101217521.

38. Hong, S.-h., J.M.H. Hendrickx, and B. Borchers, Effect of scaling transfer between evapotranspiration maps derived from LandSat 7 and MODIS images. Proc. International Society for Optical Engineering, SPIE, 2005. 5811: p. 147-158.

39. Hendrickx, J.M.H. and S.-h. Hong, Mapping sensible and latent heat fluxes in arid areas using optical imagery. Proc. International Society for Optical Engineering, SPIE, 2005. 5811: p. 138-146.

40. Bastiaanssen, W.G.M., et al., A remote sensing surface energy balance algorithm for land (SEBAL). Part 2: Validation. Journal of Hydrology, 1998. 212-213: p. 213-229.

41. Bastiaanssen, W.G.M., et al., SEBAL model with remotely sensed data to improve water-resources management under actual field conditions. J. Irrig. and Drain. Engrg., ASCE, 2005. 131(1): p. 85-93.

42. Bastiaanssen, W.G.M., et al., A remote sensing surface energy balance algorithm for land (SEBAL): 1. Formulation. Journal of Hydrology, 1998. 212-213: p. 198-212.

43. Wagenet, R.J. and J.L. Hutson, Scale-dependency of solute transport modeling/GIS applications. J. of Environmental Quality, 1996. 25: p. 499-510.

44. Feddes, R.A., P.J. Kowalik, and H. Zaradny, Simulation of field water use and crop yield. Simulation Monographs. 1978, Wageningen, The Netherlands: Pudoc.

45. Feddes, R.A., et al., Modelling soil water dynamics in the unsaturated zone - state of the art. J. Hydrology, 1988. 100: p. 69-111.

46. Belmans, J.G., J. Wesseling, and R.A. Feddes, Simulation of the water balance of a cropped soil, SWATRE. J. of Hydrology 1983. 63: p. 271-286.

47. Allen, R.G., Using the FAO-56 dual crop coefficient method over an irrigated region as part of an evapotranspiration intercomparison study. J. of Hydrology, 2000. 229: p. 27-41.

48. Crago, R.D., Conservation and variability of the evaporative fraction during the daytime J. of Hydrol., 1996. 180 : p. $173-194$.

49. Brutsaert, W. and M. Sugita, Application of self-preservation in the diurnal evolution of the surface energy budget to determine daily evaporation. J. of Geophysical Res. , 1992. 97:D17: p. 18.377-18.382.

50. Boni, G., D. Entekhabi, and F. Castelli, Land data assimilation with satellite measurements for the estimation of surface energy balance components and surface control on evaporation. Water Res. Res., 2001. 37(6): p. 1713-1722

51. Smith, E.A., et al., Area-averaged surface fluxes and their time-space variability over the FIFE experimental domain. J. of Geophysical Res., 1992. 97(D17): p. 18,599-18,622.

52. Bolle, H.-J., et al., EFEDA: European field experiment in a desertification-threatened area. Ann. Geophys., 1993.11 : p. 173-189.

53. Allen, R.G., M. Tasumi, and R. Trezza, Satellite-based energy balance for mapping evapotranspiration with internalized calibration (METRIC) - Model. Journal of Irrigation and Drainage Engineering, 2007. 133: p. 380-394.

54. Bastiaanssen, W.G.M., D.J. Molden, and I.W. Makin, Remote sensing for irrigated agriculture: examples from research and possible applications. Agricultural Water Management, 2000. 46(2): p. 137-155.

55. Engle, E.M., et al., Chapter 11. Digital soil boundary detection using quantitative hydrologic remote sensing, in Digital Soil Mapping: Bridging Research, Environmental Application, and Operation, J.L. Boettinger, et al., Editors. 2010, Springer p. $123-134$. 